\title{
A Trickle-Down Model of Task and Development I-Deals
}

Paper to be published in Human Relations

\section{Yasin Rofcanin (corresponding author)}

Reader in Organizational Behavior and Human Resource Management University of Bath, School of Management, the UK

E-Mail: y.rofcanin@bath.ac.uk

\section{Mireia Las Heras}

Associate Professor of Managing People in Organizations

IESE Business School, University of Navarra, Spain

E-Mail: mlasheras@iese.edu

\section{P. Matthijs Bal}

Professor of Responsible Management

Lincoln International Business School

University of Lincoln, Lincoln, UK

E-mail: ․ㅡal@lincoln.ac.uk

\section{Beatrice Van der Heijden}

Full Professor of Strategic HRM

1. Radboud University Nijmegen

Institute for Management Research

E-mail: b.vanderheijden@fm.ru.nl

2. Open University of the Netherlands

3. Kingston University, London, UK

\section{Didem Taser Erdogan}

Ph.D. Candidate

Human Resource Management

King's Business School, London, the UK

E-mail: didem.taser@kcl.ac.uk 


\title{
A Trickle-Down Model of Task and Development I-Deals
}

\author{
Abstract \\ In today's competitive landscape, employees increasingly negotiate idiosyncratic deals \\ (i-deals), referring to personalized work arrangements that address recipients' unique work \\ needs and preferences (Rousseau et al., 2006). While i-deals unfold in a dyadic context \\ between subordinates and their managers, the consequences of i-deals concern everyone \\ including co-workers and the organisation. Focusing on task and development i-deals, we \\ propose a trickle-down model to explore whether and how organisations benefit from i-deals. \\ First, we argue that managers' task and development i-deals cascade down to their \\ subordinates, leading them to have similar i-deals with downstream consequences for co- \\ workers and the organisation. Furthermore, we propose that effective implementation of task \\ and development i-deals are context-specific: we integrate the role of managers' servant \\ leadership as a boundary condition to explore the association between managers' and \\ subordinates' task and development i-deals. We also integrate subordinates' prosocial motives \\ to explore the association between subordinates' task and development i-deals and their work \\ outcomes. We draw on work adjustment, social learning (SLT) and social information \\ processing (SIP) theories to study our proposed associations. The results of a matched \\ employee-manager dataset collected in the Philippines support our hypothesized model. This \\ study contributes to i-deals research by: 1) testing whether and how task and development i- \\ deals can be mutually beneficial for all the involved parties; and 2) revealing how the context, \\ at the individual level, explains how and when task and development i-deals can best be \\ implemented in workplaces. This study highlights that individualization of HR practices need \\ not be a zero-sum game.
}

Key words: Task i-deals, servant leadership, prosocial motives, work performance, socially connecting behaviours. 


\section{A Trickle-Down Model of Task and Development I-Deals}

In the context of changing careers and dynamic work settings (Bidwell and Briscoe, 2010; Eurostat, 2013), differentiating employee treatment has inevitably become an important part of managerial practice (Liao et al., 2017). Referred to as personalized work arrangements negotiated between employees and their managers (Rousseau, 2005), idiosyncratic deals (i-deals) commonly take the form of task and development i-deals, providing employees with training, development and career growth opportunities, or flexibility i-deals regarding when and where work is carried out (Rosen et al., 2013).

An implicit assumption in i-deals research has been that these deals are likely to hamper team cohesion and effective organisational functioning because they are unique resources allocated to a focal employee in a competitive fashion (Rousseau and Tomprou, 2016), depriving co-workers of similar benefits (Marescaux et al., 2017) and leading to negative reactions among them (Liu et al., 2009). Interestingly, however, i-deals theory proposes that, although these deals unfold in a dyadic form of relationship between managers and their subordinates, they have positive effects and these go beyond the focal employee and the manager; contributing to overall team effectiveness and functioning of the organisation (Bal and Rousseau, 2015). Intrigued by this paradox, in this research our first goal is to explore a trickle-down model of task and development i-deals. The core premise of trickledown models is that the perceptions, attitudes or behaviours of one individual (usually a manager) cascades down through a second individual (usually a subordinate), which then influence the behaviours of the subordinate and others (Wo et al., 2015). Focusing on managers who have the ultimate resources and power to grant task and development i-deals to their subordinates (Rofcanin et al., 2017) and who, at the same time, can be the recipients of similar i-deals from their own managers; we ask the question whether and how do managers' task and development i-deals trickle-down to their subordinates? This process may lead to subordinates obtaining similar deals with downstream consequences that impact on the focal 
employee, co-workers and the overall organisation. Our focus on a trickle-down model contributes to i-deals literature by highlighting that, organisations indeed experience the benefits from granting task and development i-deals to its employees (Liao et al., 2016). This is important because i-deals are costly to organisations; it takes time and effort to achieve effective implementation of i-deals (Kroon et al., 2015; Ng, 2017).

I-deals are context-dependent, and individual level factors are likely to influence how they are obtained and implemented effectively (Liao et al., 2016). Our second goal is therefore to investigate contextual conditions that explain how and when managers' task and development i-deals trickle down to subordinates. First, we integrate the role of managers' servant leadership as a boundary condition and propose that for managers who are characterized by servant leadership (i.e., empathy and humility; Liden et al., 2014b), the positive association between managers' and their subordinates' task and development i-deals is likely to be stronger. This explains how trickle-down unfolds from the perspective of managers. Second, we extend our model to incorporate a particular type of motivation subordinates' prosocial motives - as a boundary condition, in order to contribute to understanding of when the recipients of task and development i-deals engage in socially connecting behaviours, exhibit better work performance and are seen as promotable employees. Our focus on managers' servant leadership and subordinates' prosocial motives emphasizes sharing with and caring for co-workers, underscoring the importance of resourceful and supportive work environment to enable task and development i-deals effectively (Rousseau et al., 2006). More broadly, our study underscores that individualized HR practices, as in the case of i-deals, need not be a zero-sum game (Bal and Lub, 2015; Marescaux et al., 2015). We develop the background for our conceptual model (Figure 1) in the next sections. 
Insert Figure 1 here

Theoretical background

\section{I-deals theory}

I-deals are defined as 'voluntary, personalized agreements of a non-standard nature negotiated between individual employees and their employers regarding terms that benefit each party’ (Rousseau, 2005: 23). I-deals are marked by three key features: they are negotiated individually, they are intended to be beneficial to everyone, including co-workers and the organisation, and they vary in terms of scope (Liao et al., 2016). Such deals may take the form of flexibility i-deals, providing employees with flexibility in location or schedule, financial package i-deals, offering employees individualized compensation or pay raise, or task and work responsibility i-deals (i.e., task and development i-deals), offering employees training, development or career growth opportunities (Rosen et al., 2013).

In this study, we focus on task and development responsibility i-deals. The content and characteristics of task and development i-deals are intended to develop employees' skills, abilities and job competence (Rosen et al., 2013), enabling the recipients to achieve a better person-job fit (Bal and Dorenbosch, 2015), thereby contributing to recipients' work performance and productivity (e.g., $\mathrm{Ng}$ and Lucianetti, 2016). On the contrary, flexibility ideals are primarily aimed at enabling the recipients achieve work-life balance (Hornung et al., 2009) and contribute to their family domains (e.g., Las Heras et al., 2017a). I-deals related to financial incentives and promotions (financial package i-deals) are challenging to observe because recipients tend to refrain from requesting and displaying their financial related i-deals to others such as pay raise or compensation package that are tailored to their unique contributions (Marescaux et al., 2017; Raets et al., 2017). Given that the main aim of this study is to explore how i-deals contribute to effective organizational functioning, our focus on task and development i-deals is more proximal and key than exploring the consequences of 
flexibility i-deals.

\section{Hypothesis development}

Direct associations: Manager task and development $i$-deals, subordinate task and development i-deals and subordinate work outcomes.

We expect managers' task and development i-deals to be positively associated with subordinates' work performance, career promotability and socially connecting behaviours. Our argument is based on the work-adjustment theory (Baltes et al., 1999) which underlines that employees, who have the opportunities to adjust their tasks and work toward their individualised skills and capabilities, become highly motivated and successful in their work and careers. This is because these employees are likely to achieve a better correspondence between what they want from their tasks and work and what they are capable of doing (Allen et al., 2013). Better fit facilitates them to have more energy and focus to invest in their work and their careers and create a more positive and resourceful work environment (Baltes et al., 1999). Drawing on this logic, we argue that task and development i-deals are resources that provide managers the opportunities to grow at work, develop their skills and achieve better person-job fit. Enjoying the self-growth opportunities emanating from their own task and development i-deals, managers are likely to be equipped with tools (e.g., knowledge on a new software use), skills (e.g., analytical skills in decision making) and capabilities (e.g., managing virtual teams globally) that contribute to and develop the work performance of their subordinates. This is in line with the idea that managers, in their position to act as role models and hold power, influence the availability of job resources at work and impact on the performance of their subordinates through creating more resources for them (e.g., Breevaart and Bakker, 2013).

Furthermore, working on tasks and projects that make use of their unique skillsets, managers are likely to appreciate and invest in personalized careers. Experiencing the benefits 
of better person-job fit that task and development i-deals provided to managers, they are likely to set examples for and guide their subordinates through the same path, guiding them to be promotable. Finally, better correspondence between managers' skills, responsibilities and their tasks is expected to lead to a sense of control, autonomy, increased well-being, less stress, all of which create a supportive work environment. Working in resourceful and supportive work environment, the subordinates of managers with task and development ideals are likely to engage in prosocial behaviours such as helping their colleagues and caring for their well-being, reflecting the norms of such a resourceful work unit (e.g., Halbesleben, 2010). Drawing on this line of thinking, we hypothesize:

Hypothesis 1: There is a positive association between managers' task and development i-deals and subordinates' work performance, career promotability and socially connecting behaviours.

One potential mechanism that may account for our proposed direct associations is subordinates' task i-deals. We build on social learning theory (SLT; Bandura, 1977, 2006) and social information processing theory (SIP; Salancik and Pfeffer, 1978) to propose a positive association between managers' and subordinates' task and development i-deals. According to SIP theory, employee perceptions are influenced by informational cues present in their immediate work environments (Salancik and Pfeffer, 1983; Weick et al., 2005). The core premise of SIP is that informational cues from the work context may be disentangled into information from the people and information from the broader organizational context (Weick et al., 2005). Among the people who generate cues, managers are crucial parties in shaping the perceptions of their subordinates. This is, firstly, because of their power in the hierarchy of subordinate-supervisor relationships, and secondly because they are seen as linchpins between organizations and subordinates (Kossek et al., 2011). In delineating the association between manager and subordinate task and development i-deals, we focus on the perspectives of 
subordinates and managers. From the perspective of subordinates, they learn about the appropriateness of behaviours by observing, mimicking and emulating their managers (Bandura, 2006). Adapting the key premises of SIP and SLT to the context of our study, managers' task i-deals signal that negotiation for task and development i-deals are appropriate and in line with the norms and expectations of the work context. Supporting this, Gibson (2004) argued that witnessing co-workers successfully negotiating certain HR benefits may encourage other employees to seek similar HR benefits.

From the perspective of managers, as they are the direct recipients of task and development i-deals, managers are likely to be better positioned to understand, acknowledge and appreciate the needs of their subordinates for similar i-deals. This is because the experience of a certain need increases empathy for another person currently experiencing the same need (Batson et al., 1996). For example, a manager who develops his or her work skills via participating in a new training program is likely to encourage and facilitate similar developmental oriented task and development i-deals for his or her subordinates; with the purpose of contributing to their self-development and career growth at work. To give another example, a manager, who has been assigned a challenging task in a new project, is likely to feel that his or her skills are being fully utilized. Experiencing the benefits of a better skill-task fit, this manager is likely to acknowledge similar needs of his or her subordinates and assign them tasks that better fit their skills and abilities. Indirectly supporting this argument, a study by Las Heras et al. (2017b) demonstrated that supervisors with care giving responsibilities at home are more likely to grant schedule i-deals (a form of i-deals allowing recipients to have work schedule flexibility) to their subordinates. We thus propose:

Hypothesis 2: There is a positive association between managers' and subordinates' task and development i-deals.

The consequences of i-deals concern not only the recipient but also the co-workers as 
well as the organisation enabling these i-deals (Bal and Rousseau, 2015). With regard to employees' socially connecting behaviours, we argue that the recipients of task and development i-deals exhibit prosocial behaviours toward their co-workers. Employees with task and development i-deals are likely to feel obliged to reciprocate through positive work attitudes and behaviours (Blau, 1964; Liao et al., 2016). These i-deals involve unique and scarce resources that are allocated competitively and these deals can create costs for coworkers. For example, co-workers may feel under-recognized relative to the i-dealer (Anand et al., 2010). Furthermore, due to the i-deals of a focal employee (e.g., being re-assigned to a new project; attending a special training session during work hours), the workload of coworkers might increase (Rousseau and Tomprou, 2016). Thus, we suggest the recipients of task and development i-deals are likely to show prosocial behaviours toward their co-workers in order to eliminate any potentially negative reactions from them (Anand et al., 2010; Liao et al., 2016).

With regard to work performance, we argue that task and development i-deals facilitate subordinates' fit with their jobs and provide them with opportunities to enhance their work related abilities and skills (Bal et al., 2012; Baltes et al., 1999). For example, working on tasks that better fits focal employee's skills and abilities is likely to improve focal employees' task-related knowledge to solve work-related issues. This, in turn, may enhance work performance (De Menezes and Kelliher, 2011). As another example, participating in a customized training program is likely to equip a focal employee with new skills and contribute to his or her work performance positively. In support of this, adopting a work adjustment perspective, Bal et al. (2015) found that task and development i-deals enhance objective career success.

With regard to career promotability, we argue that task and development i-deals contribute to focal employee's career promotability. Taking on extra responsibilities beyond 
one's current work load, attending training (either on the job or off the job) regarding a unique project (i.e., development i-deals), promotion to a new position or working on tasks that address and fit focal employee's skillsets (i.e., task i-deals; Rosen et al., 2013) indicate organisation's investment in the focal employee. The recipients of task and development ideals benefits from these organisational resources which lead to promotions and professional growth (e.g. a mentor, training, or a specific assignment). Recent research has also supported that there is positive association between rewards and benefits that an organisation provides to its employees and employees' career promotability (e.g., Paustian-Underdahl et al., 2016). The meta-analysis by $\mathrm{Ng}$ et al. (2005) supports that variety of organizational sponsorship practices, such as training, development, are positively associated with recipients' career growth. We thus propose:

Hypothesis 3: Subordinates' task and development i-deals are positively associated with their work performance, career promotability and socially connecting behaviours.

Indirect association: The mediating role of subordinate task and development $i$-deals. According to the human agency principle of SLT, individuals engage in active self-reflection (Bandura, 1986); that is, their self-directed work interactions influence how they view and reflect on themselves, interact with others and behave (Bandura, 2008). Drawing on this principle, we view task and development i-deals as self-directed actions that impact on everyone, beyond focal employees and their supervisors (Bal and Rousseau, 2015). When subordinates receive task and development i-deals (e.g. job opportunities to enhance oneself; personalized tasks that match individual abilities, skills and interests), they build confidence in helping colleagues, accomplishing their tasks and advancing in their careers (Gist and Mitchell, 1992). Unique development opportunities designed to enhance employees' work skills (i.e., development i-deals) and working on tasks that provide better person-job fit (i.e., task i-deals) directly enhance their beliefs in their capacity to perform at work and their ability to contribute 
to the effective functioning of their co-workers. Research to date has focused mainly on how negative work interactions, such as abusive supervision (Bardes Mawritz et al., 2012), trickle down from managers to their subordinates, impacting on subordinates' wellbeing and functioning at work. Adopting a similar logic, with a focus on self-directed positive work interactions (i.e. task and development i-deals), we posit that managers' task and development i-deals trickle down the hierarchy, leading subordinates to obtain task and development i-deals. Consequently, we expect that subordinates will actively reflect on this positive experience, which in turn will positively impact on organizational functioning and social cohesion, as i-dealers will be more willing to help co-workers, to improve their work performance and portray an image worthy of receiving further investments.

Hypothesis 4: Subordinates' task and development i-deals mediate the positive associations between managers' task and development i-deals and subordinates' work performance, career promotability and socially-connecting behaviours.

Impact of servant leadership on the association between managers' and subordinates' task and development i-deals.

An underlying tenet of i-deals theory is that i-deals do not occur in a vacuum: their meaning and effectiveness depend on the wider relational context in which they are provided (Bal and Rousseau, 2015; Rousseau et al., 2006). Informed by i-deals theory, we investigate the effects of managers' servant leadership on the association between managers' and subordinates' task and development i-deals. We propose that for managers characterized by high servant leadership, the association between managers' and subordinates' task and development i-deals is likely to be stronger. Servant leadership is defined by the attributes of putting subordinates' work needs first, behaving ethically, helping subordinates achieve career growth and development, and empowering and creating value for the teams they lead (Greenleaf, 1977; Liden et al., 2008). Focus on service motivation differentiates servant 
leadership from other leadership frameworks (Liden et al., 2014a). Two defining features of servant leadership, empathy and humility, underline that servant leaders engage in every effort to understand and acknowledge subordinates' unique work needs by putting themselves into their shoes (Liden et al., 2014b; Hu and Liden, 2008). Our focus on these two key characteristics of servant leaders is also in line with a recent cross-cultural study on servant leadership: Mittal and Dorfman (2012) revealed that empathy and humility were among the most salient characteristics of servant leaders in Southern Asian countries, one of them being the Philippines (which is the context of our study).

Servant leaders (aim to and can) address subordinates' personalized work needs, their difficulties and personal setbacks at work when they can actually comprehend what their subordinates' real needs are and possess task knowledge and problem-solving skills to aid them grow at work (van Dierendonck, 2011). To illustrate, image a manager attending a specific training on how to integrate and use a software to boost client satisfaction. Having learnt to adapt this software into his or her business, this manager is likely to acknowledge and perceive that subordinates reporting to him or her can also attend similar trainings and learn new tools, which will eventually help their career growth (i.e., development i-deals). Or imagine another situation in which a focal manager is given the responsibility of a new challenging task (i.e., product idea generation) for the implementation of a new product. Utilizing his or her creativity and brainstorming skills; this focal manager is likely to understand and appreciate that working on tasks that fit with one's skills and abilities lead to better functioning at work. Taking into account these examples, for managers who are characterized by high servant leadership, experiencing the benefits of task and development ideals will enable them to realize that their subordinates can also benefit from similar task and development i-deals to develop their unique skills and grow at work. Enjoying the benefits of task and development i-deals (i.e., high task and development i-deals), servant leaders are 
more likely to believe in the benefits of these i-deals, and grant similar deals to their subordinates with the hope of addressing subordinates' specific work needs and helping them realize their true potential at work by enabling them to work on tasks that better fit their abilities and skillsets.

On the other hand, if managers do not prioritize the needs of their subordinates (i.e., low servant leadership), they are less likely to grant i-deals to their subordinates, because their main concern is not to serve and help their subordinates grow at work. Indirect support for our argument comes from few studies on servant and other related leadership studies, emphasizing the synergic effect of servant leadership: The study by Yoshida et al. (2014) revealed a positive interaction between servant leadership and supportive unit climate in driving employees' creativity. The study by Liao and Chuang (2007) demonstrated a positive interaction between transformational leadership and service climate on employee service performance, underlining a synergic association. More recently, the study by Chiniara and Benthein (2017) revealed that the display of servant leadership behaviours is associated with low LMX differentiation, suggesting that managers characterized by high servant leadership do not establish differentiated relationships with their subordinates. However, a key tenet of ideals is that managers appreciate and address the unique needs and preferences of their subordinates, which necessitate differentiated relationship (Anand et al., 2010, 2016). Combing these arguments, we thus hypothesize:

Hypothesis 5: Managers' servant leadership moderates the positive association between managers' and subordinates' task and development i-deals. This association is stronger for managers who are high on servant leadership.

Impact of prosocial motives on the association between subordinates' task and development ideals and work outcomes. 
We further investigate the translation of subordinates' task and development i-deals into the outcomes by integrating employees' prosocial motives as a boundary condition. SLT underlines the importance of individuals' motivation for learning, self-reflection and focus on others: 'Among the mechanisms of self-influence, none is more focal or pervading than belief in one's motivation' (Bandura, 2009: 179). In particular, from the human agency perspective of SLT, our focus on employees' prosocial motivation is relevant in exploring how employees' self-initiated actions relate to their interactions with co-workers, their functioning at work and how they are perceived by their managers in relation to career promotability. From an i-deals perspective, employees' prosocial motivation enables an exploration of characteristics of employees who are likely to help their co-workers, share the benefits of i-deals with them, hence testing the assumption that i-deals intend to benefit the team (Rofcanin et al., 2017).

Two key characteristics of prosocially motivated employees are especially relevant for our argument: a) that for prosocially motivated individuals, effort is based on the desire to benefit co-workers (Grant, 2008), and b) prosocially motivated individuals are outcomefocused in that they use their gained work, skills and competencies as instruments to the end goal of helping and benefiting co-workers (Grant, 2007). Drawing on these key characteristics, for prosocially motivated individuals (i.e., who are high on prosocial motives), having task and development i-deals, they are able to better help co-workers with their work. Employees who are prosocially driven and who experience the benefits emanating from the use of task and development i-deals are likely to acknowledge that they can help their coworkers and share with them the benefits of task and development i-deals, leading to a stronger association between subordinates' own i-deals and their socially connecting behaviours towards co-workers. To illustrate, imagine a focal employee who attends training on "advanced use of Microsoft Office". If this employee is prosocially motivated, she/he will have more options and opportunities to share with his/her co-workers what she/he has learnt 
and help them in case they face problems (i.e., development i-deals). Or imagine another situation where a focal employee has taken on a new responsibility for a project. This new responsibility is likely to enable this focal employee to learn new skills, deal with different challenges and use his or her abilities to the full potential in performing this new task (i.e., task i-deals). In these examples, task and development i-deals act as mechanisms for the recipients to reflect on their prosocial motives and project this motive onto others.

In contrast, if this focal employee who has successfully negotiated an i-deal, is not driven by prosocial motives, he/she may retain the benefits of this training or new task only to himself/herself, thereby avoiding helping and citizenship behaviours towards co-workers. Supporting our argument, Zhu and Akhtar (2012) revealed a synergic effect between prosocial motives and affect-based trust, which leads to enhanced citizenship behaviours directed at co-workers.

We furthermore argue that the positive association between subordinates' task and development i-deals and their work performance is likely to be moderated by subordinates' prosocial motives. Prosocially motivated employees put conscious and persistent efforts into contributing to the effective functioning of the organization (Sheldon and Houser-Marko, 2001). In other words, they care about contributing to their organizations through enhanced work performance (Grant and Mayer, 2009) and the use of task and development i-deals is one way for them to function better at work. Hence, for prosocially motivated employees, implementing the benefits of task and development i-deals will be easier and more effective, because they are already driven with the purpose of contributing to effective functioning of their work environment and these i-deals provides a means to achieve this goal. We therefore propose that the positive association between subordinates' task and development i-deals and their career promotability is moderated by subordinates' prosocial motives. An important component of career promotability is the worthiness of the focal employee in terms of 
receiving more investments from the organisation. By focusing their attention and efforts outwardly to benefit the organisation and co-workers (i.e., high prosocial motivation; Grant, 2007), the recipients of task and development i-deals are likely to be considered promotable for various reasons: These employees are likely to prioritize others' interest to their selfinterest and commit to the investment of the organisation by showing persistence and perseverance at work (Grant and Mayer, 2009). We set our last hypothesis as below:

Hypothesis 6: Subordinates' prosocial motivates moderate the positive association between subordinates' task and development i-deals and their outcomes (i.e. work performance, career promotability and socially connecting behaviours,). More specifically, these associations are stronger for subordinates high on prosocial motives.

\section{Methods}

\section{Design and procedure}

To test our hypothesis, we invited 762 employees and 195 work team supervisors in VESSEL, a trans-oceanic transport company with 1,986 employees in the Philippines, to participate in our study. Before collecting any data, our procedures were approved by the ethics committee of the institution of the author managing the data collection. To increase willingness to participate in and response rates to our study, we offered the head of HR a full report on employees' perceptions of work-family policies and the receipt of i-deals. Subordinates answered questions about task and development i-deals, their work motivation and their demographics. Managers reported their own task and development i-deals, their servant leadership style, and evaluated employee outcomes. We conducted power analysis (Ellis, 2010) to secure sufficient subordinate-manager dyads. Using e-mail addresses as IDs to match data provided by subordinates and their direct managers, we obtained a final usable sample of 186 matched dyads. The average age of the participating subordinates was 28.2 years $(\mathrm{SD}=5.6$ years) and 42 per cent were male. In terms of educational background of subordinates; 6 per 
cent completed high school, 57 per cent completed undergraduate, 24 per cent completed post graduates and 11 percent were categorized as "others". The average age of the participating supervisors was 39 years $(\mathrm{SD}=8.1$ years) and 50.5 per cent were male. In terms of educational background of supervisors; 1 per cent completed high school, 58 per cent completed undergraduate, 39 per cent completed post graduates and 2 percent were categorized as "others".

\section{Measures}

Unless otherwise stated, all items were measured on a seven-point Likert scale $(1=$ strongly disagree; 7 = strongly agree).

Task and development i-deals. We used six items from Rosen et al.'s (2013) scale to measure managers' and their subordinates' task and development i-deals. An example item was: "At my request, my supervisor has assigned me tasks that better develop my skills" ( $\alpha=0.89$ for managers' and 0.93 for subordinates' task i-deals).

Servant leadership. Managers evaluated their servant leadership style using seven items drawn from Liden et al. (2014b), which is a shorter form of Liden et al. (2008) and has been widely used and validated in previous research (see, for instance, Van Dierendonck, 2011). An example item was: "I put employees' interests ahead of my own interest" $(\alpha=0.97)$.

Prosocial motives. Four items from Grant's (2008) scale were used to measure employees' prosocial motives. An example item was: "I work because I want to help others through my work." $(\alpha=0.86)$.

Employee outcomes. Managers evaluated the work performance (four items; Williams and Anderson, 1991; "He/she adequately completes assigned duties"; $\alpha=0.98$ ), career promotability (four items; Thacker and Wayne, 1995, validated by Hoobler et al., 2009; "If I had to select a successor for my position, it would be him/her"; $\alpha=0.94$ ) and socially 
connecting behaviours (three items, Kiefer and Barclay, 2012; "He/she helps co-workers with their tasks"; $\alpha=0.90$ ) of their subordinates.

Controls. In line with previous research on i-deals (Anand et al., 2010), we controlled for age, gender and educational background of subordinates and their managers. Younger and male employees have been shown to be better at negotiating i-deals (Bal et al., 2012), and welleducated employees may have more power to negotiate with their managers for i-deals. We also controlled for perceived organizational support with four items (Eisenberger et al., 1986; $\alpha=0.84$ ). In supportive organizations, employees may feel more comfortable negotiating for ideals if they perceive that the organization as a whole is concerned for the wellbeing of its employees and values their contributions (Rhoades and Eisenberger, 2002). An example item was: "This organisation is sincerely concerned about my well-being." Finally, we controlled for availability of supportive HR practices with seven items (Bal et al., 2015; $\alpha=0.96$ ). An example item was: "In our organization, employees have access to supportive HR practices." As the strength and directions of the results of our analyses did not change, they were excluded from subsequent analysis to achieve simplicity and parsimony (Becker et al., 2016).

\section{Analytical strategy}

To control for the nested structure of our data (employee outcomes were evaluated by managers), we applied multi-level regression analyses using MLwiN software. In order to evaluate whether multi-level modelling was the right approach, we calculated ICC(1) values for manager-rated outcomes (Hox, 2002): 31 per cent of variance for socially connecting behaviours, 15 per cent of variance for work performance and 25 per cent of variance for subordinates' career promotabiliy were attributable to differences in managers' evaluation. These findings suggested that it was appropriate to use multi-level analysis. To adequately control for both within-group and between-group variances, we used grand-mean-centered 
estimates for all Level 1 predictors, and unit-level mean-centered estimates for all Level 2 predictors (Raudenbush and Bryk, 2002).

Consistent with recent research on multi-level mediation analysis (e.g. Preacher, 2015), we conducted Monte Carlo simulations with 20,000 iterations to obtain confidence intervals for our proposed indirect effects. In testing our moderation hypotheses, we followed the recommendations of Bauer et al. (2006). Using Dawson's (2016) suggestions to interpret the results, we plotted simple slopes at one standard deviation above and below the mean of the moderator (Aiken and West, 1991).

\section{Results}

Table 1 displays the means, standard deviations, correlations and internal reliability values of our study variables.

Insert Table 1 here

We ran confirmatory factor analyses (CFAs) to explore the factorial structures of our measures using AMOS-18 software, and followed established recommendations ( $\mathrm{Hu}$ and Bentler, 1999) to report our findings. The measurement model distinguishing between the model variables showed a satisfactory fit $\left(\chi^{2}=1046.810 ; d f=506, \chi^{2} / \mathrm{df}=2.07, \mathrm{p}<0.01 ; \mathrm{IFI}\right.$ $=0.92 ; \mathrm{CFI}=0.92 ; \mathrm{TLI}=0.90 ; \mathrm{RMSEA}=0.07)$. We then compared this model with a number of alternatives, including alternative model 1 combining managers' and subordinates' task and development i-deals into a single factor $\left(\chi^{2}=1600.456 ; d f=512, \chi^{2} / d f=3.12, \mathrm{p}<\right.$ $0.01 ; \mathrm{IFI}=0.83 ; \mathrm{CFI}=0.83 ; \mathrm{TLI}=0.80 ; \mathrm{RMSEA}=0.11)$, alternative model 2 combining subordinates' outcomes into a single factor $\left(\chi^{2}=2124.790 ; d f=517, \chi^{2} / d f=4.11, \mathrm{p}<0.01\right.$; $\mathrm{IFI}=0.75 ; \mathrm{CFI}=0.75 ; \mathrm{TLI}=0.71 ; \mathrm{RMSEA}=0.13)$ and alternative model 3 , combining all variables into a single factor $\left(\chi^{2}=4995.150 ; d f=527, \chi^{2} / d f=0=9.47, \mathrm{p}<0.01 ;\right.$ IFI $=0.30$; $\mathrm{CFI}=0.30 ; \mathrm{TLI}=0.21 ; \mathrm{RMSEA}=0.21)$. These results supported the convergent validity of our measurement model. 
Hypothesis 1 proposed that managers' task and development i-deals would be positively associated with subordinates' outcomes. The results partially support this hypothesis $(\gamma=0.28, p<0.05$ for work performance; $\gamma=0.21, p<0.05$ for career promotability; $\gamma=0.05$, n.s. for socially connecting behaviours). Hypothesis 2 proposed that managers' task and development i-deals would be positively associated with subordinates' task and development i-deals. Our findings support this hypothesis $(\gamma=0.16, p<0.01$, see Table 2, Model 1). Hypothesis 3 proposed that subordinates' task and development i-deals would be positively associated with their work outcomes. The results support this hypothesis $(\gamma=0.35 ; p<0.05$ for work performance; $\gamma=0.64, p<0.001$ for career promotability; $\gamma=$ $0.64, p<0.001$ for socially connecting behaviours; see Table 2, Models 2, 3 and 4, respectively). Hypothesis 4 proposed that managers' task and development i-deals would be related to employee outcomes indirectly via subordinates' task and development i-deals. As the confidence interval did not include values of zero for work performance $(\gamma=0.11 ; 95 \% \mathrm{CI}$ $=[0.001 / 0.132])$, career promotability $(\gamma=0.13 ; 95 \% \mathrm{CI}=[0.031 / 0.198])$ and socially connecting behaviours $(\gamma=0.11 ; 95 \% \mathrm{CI}=[0.031 / 0.196])$, hypothesis 4 is also supported. See Table 2 for details.

Hypothesis 5 proposed that managers' servant leadership would moderate the association between managers' and subordinates' task and development i-deals. The interaction term was significant, providing support for our assumption $(\gamma=0.24, p<0.001$, see Table 3, Model 1). As shown in Figure 2, for managers high on servant leadership, the association between managers' and subordinates' task and development i-deals was stronger (gradient $=1.28, \mathrm{t}=3.84, \mathrm{p}<0.001)$, and for managers low on servant leadership, the association was still positive and significant (gradient $=0.81, \mathrm{t}=3.62, \mathrm{p}<0.001$ ). Hypothesis 5 is therefore supported. 
Hypothesis 6 proposed that subordinates' prosocial motives would moderate associations between subordinates' task and development i-deals and their outcomes. The interaction term was significant for subordinates' socially connecting behaviours $(\gamma=0.24, p$ $<0.05$, Table 3, Model 4), but not for their work performance $(\gamma=0.03$, n.s., Model 2$)$ and their career promotability $(\gamma=0.07$, n.s., Model 3). For subordinates high on prosocial motivation, the association between their task and development i-deals and socially connecting behaviours was stronger (gradient $=2.35, \mathrm{t}=2.35, \mathrm{p}<0.05)$; for subordinates low on prosocial motivation, the association was also significant and positive (gradient $=1.72, \mathrm{t}=$ $2.13, \mathrm{p}<0.05)$. See Table 4 for details and Figure 3 for a visual representation of the interaction.

\section{Insert Tables 3 and 4 and Figure 3 around here}

\section{Supplementary analyses}

To support the validity of our findings, we conducted additional analyses. In alternative model 1, we explored whether the association between managers' and subordinates' task and development i-deals was stronger for employees who perceived themselves as high on prosocial motives. The findings did not support the moderating role of prosocial motives on the association between subordinates' and managers' i-deals $(\gamma=0.01, n . s$.$) . In alternative model$ 2, we explored whether managers' servant leadership moderated the positive associations between subordinates' task and development i-deals and their outcomes. None of the interaction terms was significant $(\gamma=0.08, n . s$., for subordinates' socially connecting behaviours; $\gamma=0.11$, n.s., for subordinates' work performance; $\gamma=0.05, n . s$., for subordinates' career promotability). In alternative model 3, we explored whether the mediation of subordinates' task and development i-deals was moderated by managers' servant leadership, applying Edwards and 
Lambert's (2007) procedures. Since the interaction term between subordinates' task and development i-deals and managers' servant leadership on subordinates' outcomes were not significant, this alternative model is not supported. Finally, alternative model 4 tested moderation of the mediation of subordinates' task and development i-deals by subordinates' prosocial motives. The interaction term between supervisors' task and development i-deals and subordinates' prosocial motives on subordinates' task and development i-deals was not significant, and thus this alternative model is rejected. These findings support that managers' servant leadership is a key contextual condition that (only) amplifies the positive association between managers' and subordinates' task and development i-deals while subordinates' prosocial motive is a key contextual condition that (only) explains how subordinates' task and development i-deals translate into work outcomes.

\section{Discussion}

Rousseau (2005) suggests that the triangular relationship between i-dealer, manager and co-workers influences whether and how i-deals are effective. In accordance with this and focusing on a particular type of i-deals (i.e., task and development i-deals), the main contribution of this study is that it explores a trickle-down model, providing evidence for how managers' own task and development i-deals trickle down to their subordinates with consequences for co-workers (i.e., socially connecting behaviours) and their own functioning at work (work performance and career promotability). While a focus on the trickle-down model of task and development of i-deals is novel in this research, we note that similar trickle-down models, with different mechanisms and boundary conditions, may apply to other types of ideals including flexibility (e.g., location and schedule flexibility i-deals) as well as financial package i-deals.

An important assertion in i-deals research is that while task and development i-deals may have positive effects on employees' productivity (Liao et al., 2016; $\mathrm{Ng}$ and Lucianetti, 
2016), they may have negative social consequences if they strain social relationships within a team (Greenberg et al., 2004). A recent study by $\mathrm{Ng}$ (2017) integrated the i-deals of focal employees with co-workers' experiences of witnessing others' i-deals to understand the potential negative consequences of such deals. A key finding is that perceptions of a competitive climate and feelings of being envied by co-workers explain why focal employees' i-deals may lead to increased turnover. Bal and Boehm (2017) demonstrated not only that ideals serve the individualistic needs of focal employees, but that the benefits extend to the wider organizational context by being shared among co-workers. We extend these studies and contribute to recent debates on i-deals by demonstrating that in a work climate characterized by managers' servant leadership and subordinates' prosocial motives, and hence by supportive and sharing relationships, task and development i-deals may be sought by more than one employee.

Our focus on managers, and particularly their leadership style, is important, as previous research has focused exclusively on subordinates' i-deals, overlooking the other side of the equation comprising the managers who are ultimately responsible for materializing such deals (Liao et al., 2016). A study by Rofcanin et al. (2017) reveals that how managers feel about subordinates' task and development i-deals determines their decisions to grant such i-deals, underlining the critical role of managers in materializing negotiated task and development i-deals. A study by Bal et al. (2015) revealed that when managers' support for career customization (i.e. task i-deals) is high, employees benefiting from career customization report higher levels of commitment and achieve better career success in terms of bonuses and career promotability. In relation to individualized HRM, a growing body of research (e.g. Bos-Nehles, 2010; McDermott et al., 2013) has begun to show that managers have the power to modify existing HR practices. The range of formal policies defining HR practices varies across organizations yet managers frequently shape existing HR policies by 
re-defining HR practices, giving rise to i-deals (Alfes et al., 2013; Khilji and Wang, 2006).

Regarding the role of employees' prosocial motives, our findings contribute to recent research on what seals task and work responsibility i-deals and the conditions that influence their effects on co-workers and the wider organizational context (Bal and Boehm, 2017). For example, Rofcanin et al. (2017) demonstrate that managers are more likely to grant task and development i-deals to employees who engage in socially connecting behaviours toward their co-workers, such as sharing the benefits of task and development i-deals with them. Focusing on flexibility i-deals, Collins et al. (2013) demonstrate that managers may be willing to provide i-deals (on homeworking) to their subordinates, as long as they can observe employees' performance and ensure that they are helping their co-workers. Research on flexible work practices (FWPs) reveals similar results: managers support and implement FWPs for focal employees who are less likely to disrupt team efficiency (Kossek et al., 2016; Den Dulk and De Ruijter, 2008). Our findings are in line with and expand empirical research on i-deals theory that i-deals are intended to be beneficial for co-workers. For example, Anand et al. (2010) demonstrated that i-deals impact OCB-I and OCB-O. Similarly, the findings in van der Meij and Bal (2013) revealed the positive consequences of i-deals for coworkers, as the recipients of i-deal engaged in OCBs toward their co-workers.

In relation to our focus on subordinates' prosocial motives, previous studies have focused specifically on organizational features as moderators, ignoring the potential effect of motivational factors on the employee side. Bal et al. (2012) showed that the development climate at a group level moderates the relationship between task i-deals and a desire to continue working beyond retirement age. Lemmon et al. (2016) demonstrated that organizational justice, as perceived by the employee, moderates the relationship between task i-deals and life outcomes via continuous commitment. Lastly, Bal and Boehm (2017) showed that i-deals are negatively associated with emotional exhaustion, especially in units with high 
age diversity. Our finding is particularly relevant because it reveals the importance of the motivation of employees negotiating task and development i-deals, since it either boosts or diminishes the potential benefits for co-workers and the organization. This finding echoes recent research by $\mathrm{Ng}$ and Lucianetti (2016), which shows that achievement, status and striving motivation for communion relate to task and schedule i-deals, and that through such i-deals these factors affect employees' work performance. Future studies might explore why employees obtain different types of i-deals in the first place.

From a broader perspective, we also enrich the i-deals literature by drawing on SIP and SLT. Liao et al.'s (2016) review of the i-deals literature suggests that social exchange theory (SET; Blau, 1964), and particularly reciprocity, is key to explaining how different types of i-deals are obtained and their impact on employees. However, recent empirical studies reveal that SET is insufficient to explain the effects of $i$-deals on employee outcomes (Bal et al., 2015). Conway and Coyle-Shapiro (2015) suggest that SET is not the only theory capable of explaining such effects, and that exploring other theoretical frameworks might enhance our collective understanding of the phenomenon. To contribute to filling this gap, we theorized and showed that the informational cues of task and development i-deals and the modelling behaviours of subordinates' help understand how managers' task and development i-deals trickle down to influence subordinates' similar i-deals and their functioning and interactions at work. In exploring how a trickle-down model may unfold for different types of i-deals, researchers may draw on different theoretical frameworks. For example, the Work Home-Resources Model (Ten Brummelhuis \& Bakker, 2012) may be one angle through which the trickle-down model of flexibility i-deals (schedule and location flexibilities) may be explored.

Our study also contributes to debates on the contingency approach to HR differentiation (Kaufman and Miller, 2011). These debates mainly concern the question of 
whether standardization or individualization of HR practices are more important drivers of better employee work performance in teams. The findings of our study contribute to these debates by showing that subordinates' i-deals are most effective when managers' priority is to address their subordinates' work needs and when subordinates care for and interact with their co-workers, emphasizing the importance of a supportive and relational approach by both managers and subordinates. From this perspective, the findings of this study expand recent research on individualized HRM that adopts a contingency angle. For example, Bal and Dorenbosch (2015) showed that the effects of using individualized HR practices on performance and turnover depends on employees' age. Clinton and Guest (2013) revealed that the effects of differentiated HR practices vary across different job groups. Our study is the first to go beyond individual- and team-level contingencies to understand when differentiated HR practices of managers and their subordinates are most effective for everyone.

\section{Limitations and future research suggestions}

Despite the strengths of this study, some limitations must be noted. We did not measure some of the underlying processes that support our hypotheses, for example learning by observing or role modelling in explaining the association between managers' and subordinates' task i-deals. While this approach is in line with studies that have adopted SIP and SLT as overarching frameworks (e.g. Bakker et al., 2016), examination of these processes would provide a more detailed picture of how i-deals unfold and when are they most effective.

In this study, we focus specifically on task and development i-deals. Because flexibility and financial i-deals differ in nature from task and development i-deals (Las Heras et al., 2017a), the trickle-down model we explored cannot be generalized to all types of ideals. Future studies might explore different theoretical mechanisms for the trickle-down effects of flexibility and financial i-deals. For example, the Work Home-Resources Model (the WH-R model) or work-family enrichment theories may be appropriate to explain how 
flexibility i-deals cascade down the hierarchy of the organisation.

Managers evaluated their task i-deals as well as servant leadership while subordinates evaluated their task i-deals and prosocial motives. Given the social desirability concerns (e.g., managers might have evaluated their servant leadership high), potential common-method bias (i.e., $\mathrm{CMB}$ ) issues may have been observed in our data. The results revealed that $\mathrm{CMB}$ was not a significant threat. Nevertheless, it is important for future research to explore how leadership facilities or inhibits the implementation of i-deals (measured by subordinates) and how subordinates' different motives (e.g., productivity, intrinsic, extrinsic motives measured by managers) facilitate or inhibit the implementation of $\mathrm{i}$-deals.

Furthermore, the way we hypothesized the moderating role of managers' servant leadership and subordinates' prosocial motives underline a synergistic effect. From a different angle, it may be possible to observe complementary effects where managers' servant leadership and subordinates' prosocial motives may still strengthen the proposed associations irrespective of task i-deals. Taking into account recent research which has started questioning the other side of servant leadership (Meuser et al., 2011) and prosocial motives (Grant, 2017); we suggest future research to also adopt a complementary perspective in exploring the consequences of $i$-deals.

We measured task and development i-deals using the validated scale of Rosen et al. (2013). These items measure both the extent to which employees successfully negotiated and obtained task and development i-deals. However, negotiation and obtainment are different aspects of i-deals and what is negotiated may not be obtained, with different factors influencing this process (e.g., Rofcanin et al., 2017). It will be interesting for future research to adopt a longitudinal design and explore the processual nature of i-deals, disentangling it into its various steps including negotiation and obtainment.

We investigated task and development i-deals in the under-studied context of the 
Philippines. Given that the cultural characteristics of this context emphasize high in-group collectivism and uncertainty avoidance (House et al., 2004), the practice of i-deals in these companies may not be representative of other contexts. Future research might explore the extent to which corporate and national cultural characteristics influence such i-deals.

It is worth noting that, on average, subordinates reported high levels of task and development i-deal negotiations with their managers. This is likely to have related to the most recent adoption of supportive HR policies by the company. All employees had leeway to negotiate extra responsibilities, career growth opportunities and training to upgrade their skills and abilities. While this might reduce the generalizability of our findings to other companies in the Philippines, other research conducted in a Latin American context reveals that individualized HR practices are adopted by many companies to encourage employees to achieve better person-job fit and enhance their functioning at work (e.g. Las Heras et al., 2015). Future research might investigate whether and how task and development i-deals unfold in companies where individualization of HR practices is not adopted as formal policy.

\section{Practical implications and conclusions}

The findings of this study have important managerial implications. Our findings show that multiple employees may be entitled to task and development i-deals, and that such i-deals may benefit everyone, including co-workers and organizations. Given the crucial role of teamwork and achieving enhanced work performance for organizations (Gilboa et al., 2008), task and development i-deals may constitute important intervention tools for HR departments to keep today's self-development driven and career-focused generation of employees motivated and productive at work. Our study also provides organizations and managers with information about when and how task and development i-deals might be implemented as effective

intervention tools. Specifically, under the leadership of managers possessing characteristics of servant leadership, subordinates are more likely to model and imitate their managers. Moreover, 
the impact of task and development i-deals on others is more pronounced and positive for subordinates who are prosocially driven. An implication common to these findings is that HR departments and organizations should pay particular attention to cultivating and developing a resourceful work environment encouraging support and care for others, which are indications of socially connecting behaviors (Salas and Cannon-Bowers, 2001). To facilitate the trickledown between managers and subordinates, we suggest behavioural modelling techniques which would involve viewing an appropriate model (e.g. a manager), determining how the behaviour is accomplished (i.e. the negotiation), discussing the effectiveness of the behaviour, and practising the behaviour, for example through simultaneous role plays (Gibson, 2004). To render task and development i-deals effective for everyone, we suggest 1) prioritizing recruitment of employees characterized by servant leadership and prosocial motives; 2) developing training interventions aimed at fostering helping and caring behaviours among the recipients, and 3) making such i-deal types a part of official HR programmes to help employees address their individualized work needs. 


\section{References}

Aiken LS and West SG (1991) Multiple Regression: Testing and Interpreting Interactions. Newbury Park: Sage.

Alfes K, Truss C, Soane EC, Rees C and Gatenby M (2013) The relationship between line manager behavior, perceived HRM practices, and individual performance: Examining the mediating role of engagement. Human Resource Management Journal 52(6): 839-59.

Allen TD Johnson RC Kiburz KM and Shockley KM (2013) Work-family conflict and flexible work arrangements: deconstructing flexibility. Personnel Psychology 66: 345-376.

Ambrose ML, Schminke M and Mayer DM (2013) Trickle-down effects of supervisor perceptions of interactional justice: A moderated mediation approach. Journal of Applied Psychology 98(4): 678-89.

Anand S, Vidyarthi PR, Liden RC and Rousseau DM (2010) Good citizens in poor-quality relationships: Idiosyncratic deals as a substitute for relationship quality. Academy of Management Journal 53(5): 970-88.

Anand, S., Vidyarthi, P. R., \& Park, H. S. (2016). LMX differentiation: Understanding relational leadership at individual and group levels. In T. N. E. E. Bauer, \& Berrin (Vol. Eds.), The Oxford handbook of leader-member exchange. Vol. xviii. The Oxford handbook of leader-member exchange (pp. 263-291). New York, NY, US: Oxford University Press $435 \mathrm{pp}$.

Bakker AB, Rodriguez-Muñoz A and Sanz-Vergel AI (2016) Modelling of job crafting behaviours: Implications for work engagement. Human Relations 69(1): 169-89.

Bal PM (2017) Why do employees negotiate idiosyncratic deals? An exploration of the process of i-deal negotiation. New Zealand Journal of Employment Relations, in press.

Bal PM and Boehm SA (2017) How do i-deals influence client satisfaction? The role of exhaustion, collective commitment, and age diversity. Journal of Management. DOI: $10.1177 / 0149206317710722$.

Bal PM, De Jong SB, Jansen PGW and Bakker AB (2012) Motivating employees to work beyond retirement: A multi-level study of the role of i-deals and unit climate. Journal of Management Studies 49(2): 306-31.

Bal PM and Dorenbosch L (2015) Age-related differences in the relations between individualized HRM and organizational performance: A large-scale employer survey. Human Resource Management Journal 25(1): 41-61. 
Bal PM and Lub XD (2015) Individualization of work arrangements: A contextualized perspective on the rise and use of i-deals. In: Bal PM and Rousseau DM (eds) Idiosyncratic Deals between Employees and Organizations: Conceptual Issues, Applications and the Role of Co-workers. Oxford: Taylor \& Francis Group, 52-65.

Bal PM and Rousseau DM (2015) Idiosyncratic Deals between Employees and Organizations: Conceptual Issues, Applications and the Role of Co-workers. Oxford: Taylor \& Francis Group.

Bal PM, Van Kleef MV and Jansen PGW (2015) The impact of career customization on work outcomes: Boundary conditions of manager support and employee age. Journal of Organizational Behavior 36(3): 421-40.

Baltes BB Briggs TE Huff JW Wright JA and Neuman GA (1999) Flexible and compressed workweek schedules: A meta-analysis of their effects on work-related criteria. Journal of Applied Psychology 84(4): 496-513.

Bandura A (1971) Social Learning Theory. New York, NY: General Learning Press.

Bandura A (1986) Social Foundations of Thought and Action: A Social Cognitive Theory. Englewood Cliffs, NJ: Prentice-Hall.

Bandura A (2008) The reconstrual of 'free will' from the agentic perspective of social cognitive theory. In: Baer J, Kaufman JC and Baumeister RF (eds) Are We Free? Psychology and Free Will. Oxford: Oxford University Press, 86-127.

Bandura A (2009) Cultivate self-efficacy for personal and organizational effectiveness. In: Locke EA (ed.) Handbook of Principles of Organization Behavior, 2nd edn. New York, NY: Wiley, 179-200.

Batson, C.D., Sympson, S.C., Hindman, J.L., Decruz, P., Todd, R.M., Weeks, J.L., Jennings, G. and Burris, C.T. (1996). "I've been there too": effect on empathy of prior experience with a need'. Personality and Social Psychology Bulletin, 22(5): 474-482.

Bardes Mawritz M, Mayer DM, Hoobler JM, Wayne SJ and Marinova SV (2012) A trickledown model of abusive supervision. Personnel Psychology 65(2): 325-57.

Bauer DJ, Preacher KJ and Gil KM (2006) Conceptualizing and testing random indirect effects and moderated mediation in multilevel models: New procedures and recommendations. Psychological Methods 11(2): 142-63.

Becker TE, Atinc G, Breaugh JA, Carlson KD, Edwards JR and Spector PE (2016) Statistical control in correlational studies: 10 essential recommendations for organizational researchers. Journal of Organizational Behavior 37(2): 157-67. 
Bidwell M and Briscoe F (2010) The dynamics of interorganizational careers. Organization Science 21(5): 1034-53.

Blau PM (1964) Exchange and Power in Social Life. New York, NY: John Wiley \& Sons.

Bos-Nehles A (2010) The line makes the difference: Line managers as effective HR partners. Unpublished doctoral thesis, University of Twente, Enschede, Netherlands.

Breevaart K and Bakker AB (2013) How leaders influence their followers work engagement. European Work and Organizational Psychology in Practice 5: 31-35.

Buss DM (1987) Selection, evocation, and manipulation. Journal of Personality and Social Psychology 53(6): 1214-21.

Call ML, Nyberg AJ and Thatcher SMB (2015) Stargazing: An integrative conceptual review, theoretical reconciliation, and extension for star employee research. Journal of Applied Psychology 100(3): 623-40.

Chiniara M and Bentein K (2017). Servant leadership advantage: When perceiving low differentiation in leader-member relationship quality influneces team cohesion, team task performance and service OCB. Leadership Quarterly, doi: http://dx.doi.org/10.1016/j.leaqua.2017.05.002.

Clinton M and Guest DE (2013) Testing universalistic and contingency HRM assumptions across job levels. Personnel Review 42(5): 529-51.

Collins AM, Cartwright S and Hislop D (2013) Homeworking: Negotiating the psychological contracts. Human Resource Management Journal 23(2): 211-25.

Conway N and Coyle-Shapiro J (2015) Not so i-deal: A critical review of idiosyncratic-deals theory and research. In: Bal PM and Rousseau DM (eds) Idiosyncratic Deals between Employees and Organizations: Conceptual Issues, Applications, and the Role of Coworkers. London: Psychology Press, 25-37.

Dawson J (2016) Interpreting interaction effects. Available at: http://www.jeremydawson.com/slopes.htm.

De Menezes LM and Kelliher C (2011) Flexible working and performance: A systematic review of the evidence for a business case. International Journal of Management Reviews 13(4): $452-74$.

Den Dulk L and De Ruijter J (2008) Managing work-life policies: Disruption versus dependency arguments. The International Journal of Human Resource Management 19(7): $1222-36$. 
Edwards JR and Lambert LS (2007) Methods for integrating moderation and mediation: A general analytical framework using moderated path analysis. Psychological Methods 12(1): $1-22$.

Eisenberger R, Huntington R, Hutchison S and Sowa D (1986) Perceived organizational support. Journal of Applied Psychology 71(3): 500-507.

Ellis PD (2010) The Essential Guide to Effect Sizes: Statistical Power, Meta-Analysis, and the Interpretation of Research Results. Cambridge: Cambridge University Press.

Eurostat (2013) Statistics explained: Labour market. Available at: http://epp.eurostat.ec.europa.eu/statistics_explained/index.php/Category:Labour_market.

Gibson SK (2004) Social learning (cognitive) theory and implications for human resource development. Advances in Developing Human Resources 6(2): 193-210.

Gilboa S, Shirom A, Fried Y and Cooper C (2008) A meta-analysis of work demand stressors and job performance: Examining main and moderating effects. Personnel Psychology 61(2): $227-71$.

Gist ME and Mitchell TR (1992) Self-efficacy: A theoretical analysis of its determinants and malleability. Academy of Management Review 17(2): 183-211.

Grant, A. M. (2007). Relational job design and the motivation to make a prosocial difference. Academy of Management Review 32: 393-417.

Grant AM (2008) Does intrinsic motivation fuel the prosocial fire? Motivational synergy in predicting persistence, performance, and productivity. Journal of Applied Psychology 93(1): $48-58$.

Grant AM and Mayer DM (2009) Good soldiers and good actors: Prosocial and impression management motives as interactive predictors of affiliative citizenship behaviors. Journal of Applied Psychology 94(4): 900-12.

Grant AM, Parker SK and Collins CG (2009) Getting credit for proactive behavior: Supervisor reactions depend on what you value and how you feel. Personnel Psychology 62(1): 31-55.

Greenleaf RK (1977) Servant Leadership: A Journey into the Nature of Legitimate Power and Greatness. New York, NY: Paulist Press.

Guerrero S, Bentein K and Lapalme M-E (2014) Idiosyncratic deals and high performers' organizational commitment. Journal of Business and Psychology 29(2): 323-34.

Guerrero S and Challiol-Jeanblanc H (2016) Idiosyncratic deals and helping behavior: The moderating role of i-deal opportunity for co-workers. Journal of Business \& Psychology 31(3): 433-43. 
Halbesleben CRB Bowler WMB Bolino MC Turnley WH (2010) Organizational concern, prosocial values or impression management? How supervisors attribute motives to organizational citizenship behaviour. Journal of Applied Social Psychology 40(6): 1450-89.

Hoobler JM, Wayne SJ and Lemmon G (2009) Bosses' perceptions of family-work conflict and women's promotability: Glass ceiling effects. Academy of Management Journal 52(5): 939957.

Hornung S, Rousseau DM, Glaser J, Angerer P and Weigl M (2010) Beyond top-down and bottom-up work redesign: Customizing job content through idiosyncratic deals. Journal of Organizational Behavior 31(2): 187-215.

House RJ, Hanges PJ, Javidan M, Dorfman P and Gupta V, eds (2004) Culture, Leadership, and Organizations: The GLOBE Study of 62 Societies. Thousand Oaks, CA: Sage.

Business 37(1): 3-10.

Hox J (2002) Multilevel Analysis: Techniques and Applications. Mahwah, NJ: Erlbaum.

$\mathrm{Hu} \mathrm{J}$ and Liden RC (2011) Antecedents of team potency and team effectiveness: An examination of goal and process clarity and servant leadership. Journal of Applied Psychology 96(4): 851-62.

Hu L-T and Bentler PM (1999) Cutoff criteria for fit indices in covariance structure analysis: Conventional criteria versus new alternatives. Structural Equation Modeling 6(1): 1-55.

Kaufman BE and Miller BI (2011) The firm's choice of HRM practices: Economics meets strategic human resource management. Industrial and Labor Relations Review 64(3): 52657.

Khilji S and Wang X (2006) 'Intended' and 'implemented' HRM: The missing linchpin in strategic human resource management research. The International Journal of Human Resource Management 17(7): 1171-89.

Kiefer T and Barclay L (2012) Understanding the mediating role of toxic emotional experiences in the relationship between negative emotions and adverse outcomes. Journal of Occupational and Organizational Psychology 85(4): 600-25.

Kossek EE, Ollier-Malaterre A, Lee MD, Pichler S and Hall DT (2016) Line managers' rationales for professionals' reduced-load work in embracing and ambivalent organizations. Human Resource Management 55(1): 143-71.

Kossek EE, Pichler S, Bodner T and Hammer LB (2011) Workplace social support and workfamily conflict: A meta-analysis clarifying the influence of general and work-family specific supervisor and organizational support. Personnel Psychology 64(2): 289-313. 
Kroon B, Freese C and Schalk R (2015) A strategic HRM perspective on i-deals. In: Bal M and Rousseau DM (eds) Idiosyncratic Deals between Employees and Organizations: Conceptual Issues, Applications, and the Role of Coworkers. Hove: Psychology Press, 73-91.

Las Heras M, Bosch MJ and Raes AM (2015) Sequential mediation among family friendly culture and outcomes. Journal of Business Research 68(11): 2366-73.

Las Heras M, Rofcanin Y, Bal MB and Stollberger J (2017a) How do flexibility i-deals relate to work performance? Exploring the roles of family performance and organizational context. Journal of Organizational Behavior. DOI: 10.1002/job.2203

Las Heras, M., van der Heijden, B., de Jong, J., \& Rofcanin, Y., (2017b). 'Handle with care': The mediating role of I-deals in the relationship between supervisors' care-giving responsibilities and employee outcomes. Human Resource Management Journal 27(1): 335349.

Lemmon G, Westring A, Michel EJ, Wilson MS and Glibkowski BC (2016) A cross-domain exploration of performance benefits and costs of idiosyncratic deals. Journal of Leadership \& Organizational Studies 23(4): 440-55.

Liao H, and Chuang A (2007) Transforming service employees and climate: A multilevel, multisource examination of transformational leadership in building long-term service relationships. Journal of Applied Psychology 92(4): 1006-1019.

Liao C, Wayne SJ, Liden RC and Meuser JD (2017) Idiosyncratic deals and individual effectiveness: The moderating role of leader-member exchange differentiation. Leadership Quarterly. DOI: 10.1016/j.leaqua.2016.10.014

Liao C, Wayne S and Rousseau DM (2016) Idiosyncratic deals in contemporary organizations: A qualitative and meta-analytical review. Journal of Organizational Behavior 37(S1): S929.

Liden RC, Panaccio A, Meuser JD, Hu J and Wayne SJ (2014a) Servant leadership: Antecedents, processes, and outcomes. In D. V. Day (Ed.), The Oxford handbook of leadership and organizations: 357-379. Oxford, UK: Oxford University Press.

Liden RC, Wayne SJ, Liao C and Meuser JD (2014b) Servant leadership and serving culture: Influence on individual and unit performance. Academy of Management Journal 57(5): $1434-52$.

Liden RC, Wayne SJ, Meuser JD, Hu J, Wu J and Liao C (2015) Servant leadership: Validation of a short form of the SL-28. Leadership Quarterly 26(2): 254-69. 
Liden RC, Wayne SJ, Zhao H and Henderson D (2008) Servant leadership: Development of a multidimensional measure and multilevel assessment. Leadership Quarterly 19(2): 161-77.

Lohrey S (2015) The effect of servant leadership on follower performance and wellbeing: Underlying mechanisms, boundary conditions and the role of training. Aston University, Unpublished Ph.D. Dissertation.

Marescaux E, De Winne S and Sels L (2013) HR practices and affective organizational commitment: (When) does HR differentiation pay off? Human Resource Management Journal 23(4): 329-45.

Marescaux E, De Winne S and Sels L (2017) Idiosyncratic deals from a distributive justice perspective: Examining co-workers' voice behavior. Journal of Business Ethics: DOI: 0.1007/s10551-016-3400-7.

Marwitz MB, Mayer DM, Hoobler JM, Wayne SJ. and Marinova SV (2012) A trickle-down model of abusive supervision. Personnel Psychology 65(2): 325-57.

McDermott AM, Conway E, Rousseau DM and Flood PC (2013) Promoting effective psychological contracts through leadership: The missing link between HR strategy and performance. Human Resource Management 52(2): 289-310.

Meuser JD, Liden RC, Wayne SJ and Henderson DJ (2011) Is servant leadership always a good thing? The moderating influence of servant leadership prototype. Paper presented at the Annual Meeting of the Academy of Management, San Antonio, Texas.

Mittal R and Dorfman, PW (2012). Servant leadership across cultures. Journal of World Business 47, 555-570.

Ng TWH (2017) Can idiosyncratic deals promote perceptions of competitive climate, felt ostracism, and turnover? Journal of Vocational Behaviour 99(1): 118-31.

Ng TWH and Lucianetti L (2016) Goal striving, idiosyncratic deals and job behaviour. Journal of Organizational Behavior 37(1): 41-60.

Ng, TWH, Eby L, Sorensen K and Feldman DC (2005) Predictors of objective and subjective career success: a meta-analysis. Personnel Psychology 58(2): 367-408.

Paustian-Underdahl, SC, Halbesleben JRB, Carlson DW and Kacmar KM (2016) The workfamily interface and promotability: Boundary integration as a double-edge sword. Journal of Management 42(2): 960-981.

Peng H and Wei H (2016) Trickle-down effects of perceived leader integrity on employee creativity: A moderated mediation model. Journal of Business Ethics, DOI 10.1007/s10551016-3226-3 
Postmes T, Haslam SA and Swaab R (2005) Social influence in small groups: An interactive model of social identity formation. European Review of Social Psychology 16(1): 1-42.

Preacher KJ (2015) Advances in mediation analysis: A survey and synthesis of new developments. Annual Review of Psychology 66(1): 825-52.

Raudenbush SW and Bryk AS (2002) Hierarchical Linear Models: Applications and Data Analysis Methods, 2nd edn. Newbury Park, CA: Sage.

Rhoades L and Eisenberger R (2002) Perceived organizational support: A review of the literature. Journal of Applied Psychology 87(4): 698-714.

Rofcanin Y, Kiefer T and Strauss K (2017) What seals the I-deal? Exploring the role of employees' behaviours and managers' emotions. Journal of Occupational and Organizational Psychology 90(2): 203-24.

Rosen CC, Slater DJ, Chang D and Johnson RE (2013) Let's make a deal: Development and validation of the ex post i-deals scale. Journal of Management 39(3): 709-42.

Rousseau DM (2005) I-deals: Idiosyncratic Deals Employees Bargain for Themselves. New York, NY: M. E. Sharpe.

Rousseau DM, Ho VT and Greenberg J (2006) I-deals: Idiosyncratic terms in employment relationships. Academy of Management Review 31(4): 977-94.

Rousseau DM and Tomprou, M (2016). Negotiating flexible and fair idiosyncratic deals (ideals). Organizational Dynamics, doi: 10.1016/j.orgdyn.2016.07.004.

Salancik GR and Pfeffer J (1978) A social information processing approach to job attitudes and task design. Administrative Science Quarterly 23(2): 224-53.

Salas E and Cannon-Bowers JA (2001) The science of training: A decade of progress. Annual Review of Psychology 52(1): 471-99.

Sheldon KM and Houser-Marko L (2001) Self-concordance, goal attainment and the pursuit of happiness: Can there be an upward spiral? Journal of Personality and Social Psychology 80(1): 152-65.

Ten Brummelhuis LL Bakker AB (2012) A resource perspective on the work-home interface: The work-home resources model. American Psychologist 67: 545- 556.

Van der Meij K and Bal PM (2013) De ideale 'idiosyncratic-deal' Gedrag en Organisatie 26: 156-181.

Van Dierendonck D (2011) Servant leadership: A review and synthesis. Journal of Management 37(4): 1228-61.

Wang Z, Xu H and Liu Y (2016) How does ethical leadership trickle down? Test of an integrative-dual process. Journal of Business Ethics. doi: 10.1007/s10551-016-3361-x 
Weick KE, Sutcliffe KM and Obstfeld D (2005) Organizing and the process of sensemaking. Organization Science 16(4): 409-21.

Williams LJ and Anderson SE (1991) Job satisfaction and organizational commitment as predictors of organizational citizenship and in-role behavior. Journal of Management 17(3): 601-17.

Wo DXH, Ambrose ML and Schminke M (2015) What drives trickle-down effects? A test of multiple mediation processes. Academy of Management Journal 58(6): 1848-68.

Yoshida DT, Sendjaya S, Hirst G and Cooper B (2014) Does servant leadership foster creativity and innovation? A multi-level mediation study of identification and prototypicality. Journal of Business Research 67: 1395-1404.

Zhu Y and Akhtar S (2014) How transformational leadership influences follower helping behavior: The role of trust and prosocial motivation. Journal of Organizational Behaviour 35(2): 373-392. 
Table 1. Means, standard deviations, reliabilities and correlations

\begin{tabular}{|c|c|c|c|c|c|c|c|c|c|c|}
\hline & Variables & Mean & S.D. & 1 & 2 & 3 & 4 & 5 & 6 & 7 \\
\hline 1 & Managers' Task and Development I-Deals & 3.78 & 0.91 & 0.89 & & & & & & \\
\hline 2 & Subordinates' Task and Development I-Deals & 6.05 & 0.61 & $0.23 * *$ & 0.93 & & & & & \\
\hline 3 & Managers' Servant Leadership & 3.86 & 0.88 & $0.42 * *$ & $0.32 * *$ & 0.97 & & & & \\
\hline 4 & Subordinates' Prosocial Motives & 6.36 & 0.84 & 0.14 & 0.02 & 0.07 & 0.86 & & & \\
\hline 5 & Subordinates' Work Performance & 4.62 & 1.39 & $0.17 *$ & $0.18^{*}$ & 0.07 & 0.04 & 0.98 & & \\
\hline 6 & Subordinates' Career Promotability & 4.86 & 1.44 & $0.15^{*}$ & $0.23 * *$ & 0.11 & 0.13 & $0.37 * *$ & 0.94 & \\
\hline 7 & Subordinates' Socially Connecting Behaviours & 5.41 & 1.37 & 0.08 & $0.22 * *$ & 0.01 & 0.14 & 0.08 & $0.44 * *$ & 0.90 \\
\hline
\end{tabular}

Notes: $\mathrm{n}=186 ; * \mathrm{p}<0.05 ; * * \mathrm{p}<0.01 ; * * * \mathrm{p}<0.001$.

Table 2. Direct and indirect effects of managers' task i-deal negotiations on subordinates' outcomes (H1, H2, H3, H4)

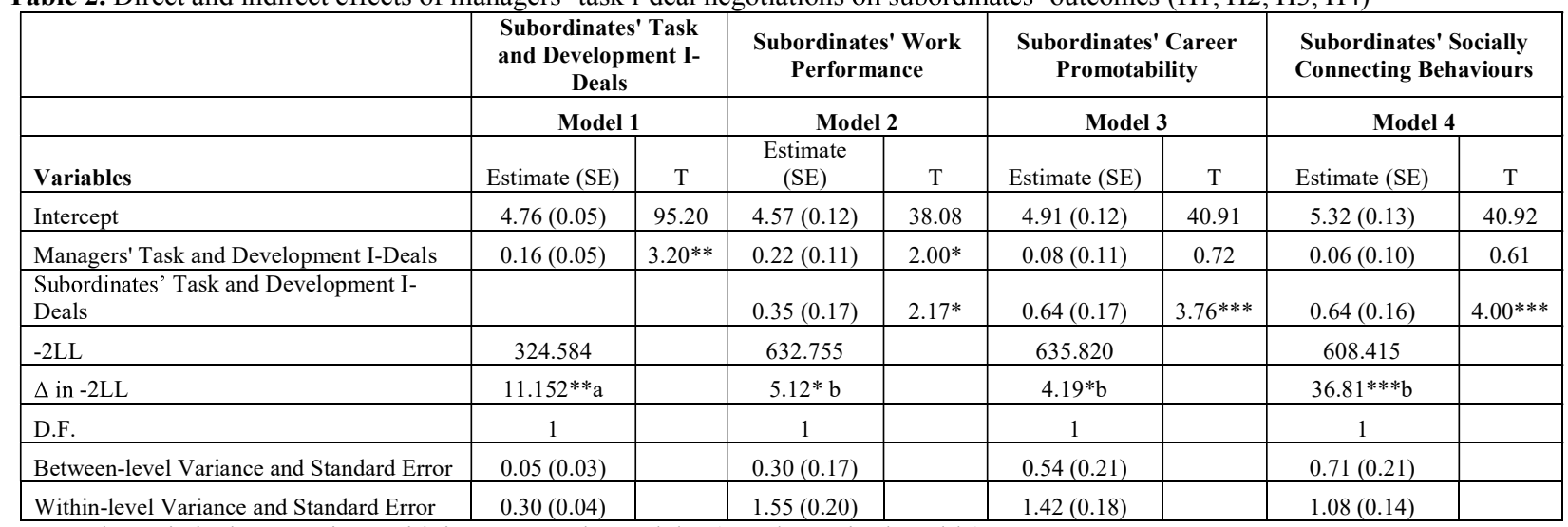

Notes. ab Statistical comparison with intercept-only model 1 (not shown in the table).

The indirect effect is calculated using an online interactive tool that generates an R score: http://quantpsy.org/medmc/medmc.htm.

For all values, gamma coefficients, their corresponding standard error and $t$ values are reported; $\mathrm{n}=186 ; * \mathrm{p}<0.05 ; * * \mathrm{p}<0.01 ; * * * \mathrm{p}<0.001$. 
Table 3. Moderating impacts of managers' servant leadership and subordinates' prosocial motives (H5, H6)

\begin{tabular}{|c|c|c|c|c|c|c|c|c|}
\hline \multirow[b]{2}{*}{ Variables } & \multicolumn{2}{|c|}{$\begin{array}{c}\text { Subordinates' Task and } \\
\text { Development I-Deals } \\
\text { (Model 1) }\end{array}$} & \multicolumn{2}{|c|}{$\begin{array}{c}\text { Subordinates' Work } \\
\text { Performance (Model 2) }\end{array}$} & \multicolumn{2}{|c|}{$\begin{array}{c}\text { Subordinates' Career } \\
\text { Promotability (Model 3) }\end{array}$} & \multicolumn{2}{|c|}{$\begin{array}{c}\text { Subordinates' Socially } \\
\text { Connecting Behaviours } \\
\text { (Model 4) }\end{array}$} \\
\hline & Estimate (SE) & $\mathbf{T}$ & Estimate (SE) & $\mathbf{T}$ & Estimate (SE) & $\mathbf{T}$ & Estimate (SE) & $\mathbf{T}$ \\
\hline Intercept & $4.03(0.05)$ & 80.60 & $4.58(0.09)$ & 38.16 & $4.78(0.13)$ & 36.76 & $5.33(0.13)$ & 41.00 \\
\hline Managers' Task and Development I-Deals & $0.12(0.05)$ & $2.41 *$ & & & & & & \\
\hline Managers' Servant Leadership & $0.11(0.06)$ & 1.83 & & & & & & \\
\hline $\begin{array}{l}\text { Managers' Task and Development I-Deals*Servant } \\
\text { Leadership }\end{array}$ & $0.24(0.06)$ & $4.00 * * *$ & & & & & & \\
\hline Subordinates' Task and Development I-Deals & & & $0.43(0.17)$ & $2.53 *$ & $0.61(0.16)$ & $3.81 * * *$ & $0.68(0.15)$ & $4.53 * * *$ \\
\hline Subordinates' Prosocial Motives & & & $0.06(0.11)$ & 0.55 & $0.23(0.12)$ & 1.92 & $0.23(0.11)$ & $2.09 *$ \\
\hline $\begin{array}{l}\text { Subordinates' Task and Development I- } \\
\text { Deals*Prosocial Motives }\end{array}$ & & & $0.03(0.19)$ & 0.16 & $0.07(0.17)$ & 0.41 & $0.24(0.10)$ & $2.40^{*}$ \\
\hline$-2 \mathrm{LL}$ & 304.180 & & 756.292 & & 642.181 & & 602.580 & \\
\hline$\Delta$ in $-2 L L$ & $4.34 * a$ & & $3.02 b$ & & $3.22 c$ & & $5.01 * d$ & \\
\hline D.F. & 1 & & 1 & & & & 1 & \\
\hline Between-level Variance and Standard Error & $0.08(0.03)$ & & $0.25(0.16)$ & & $0.57(0.21)$ & & $0.71(0.20)$ & \\
\hline Within-level Variance and Standard Error & $0.25(0.03)$ & & $1.61(0.20)$ & & $1.37(0.18)$ & & $1.06(0.14)$ & \\
\hline
\end{tabular}

Notes. $a, b, c, d$ : Statistical comparison with intercept-only model 1 (not shown in the table).

The first step of moderation analyses is not shown in the table and the models for each outcome variable include the first steps of moderation analyses.

For all values, gamma coefficients, their corresponding standard error and $T$ values are reported $\mathrm{n}=186 ; * \mathrm{p}<0.05 ; * * \mathrm{p}<0.01 ; * * * \mathrm{p}<0.001$. 
Figure1. Conceptual model

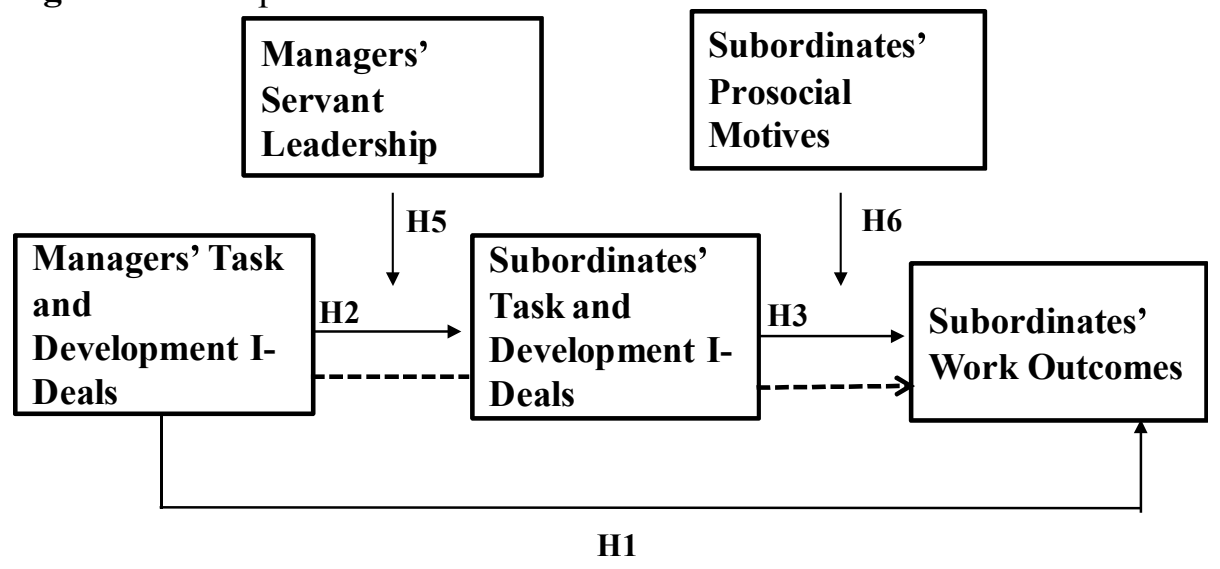

Notes. H4: Dotted lines denote mediation of subordinates' task i-deals between managers' task i-deals and subordinates' outcomes.

Figure 2. Interaction of managers' servant leadership and their task and development i-deals on subordinates' task and development i-deals

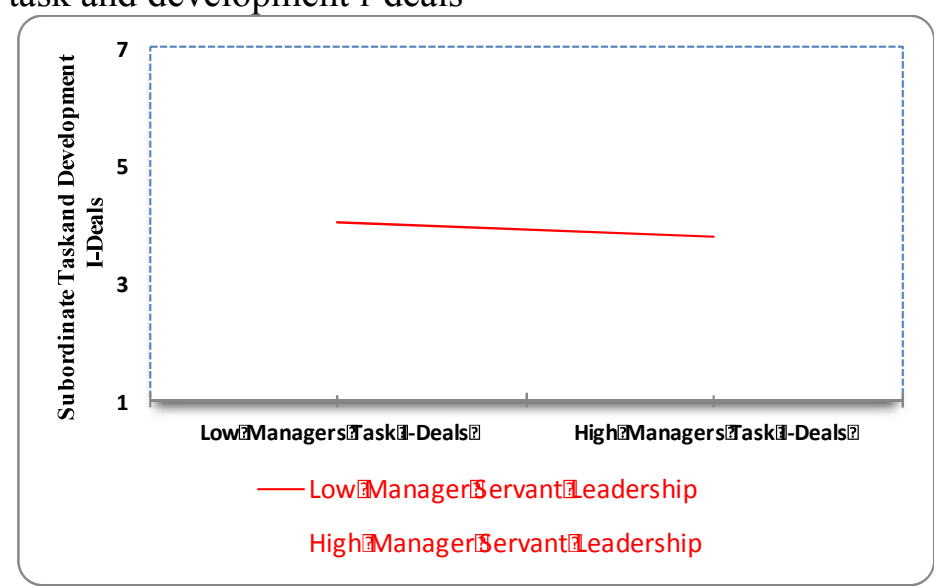

Figure 3. Interaction of subordinates' prosocial motives and subordinates' task and development i-deals on their socially connecting behaviours

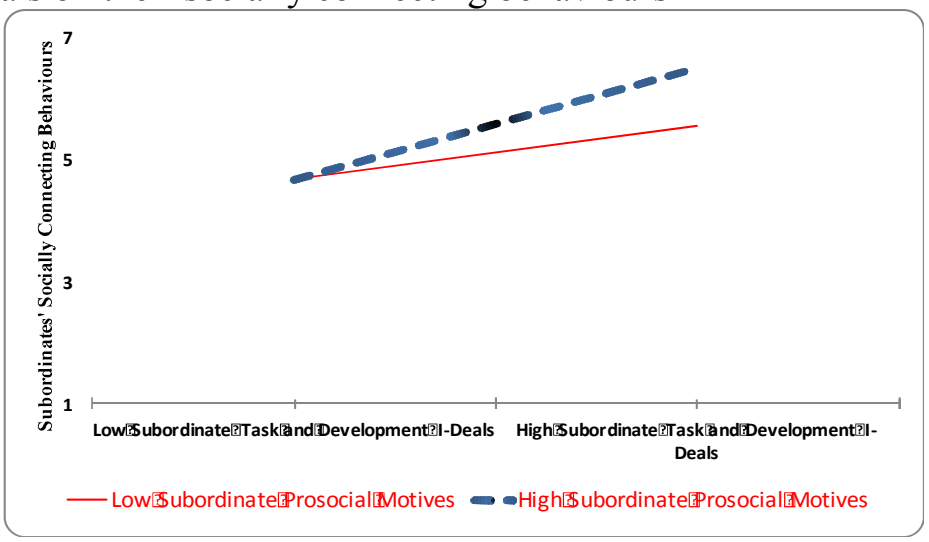

